\title{
La acumulación social del conocimiento: Una perspectiva interdisciplinar
}

\author{
Pedro C. Marijuán \\ Seminario Interdisciplinar. \\ Departamento de Electrónica e Informática, \\ Centro Politécnico Superior, Universidad de Zaragoza.
}

\subsection{Resumen}

Se establece una conexión entre los procesos de conocimiento que acontecen en el nivel más inferior de las sociedades vivas — las bacterias - y la sofisticada sociedad de los científicos desde la perspectiva del paradigma "vida artificial". En primer lugar, se exploran las sociedades bacterianas desde una perspectiva informacional. Seguidamente, se considera la sociedad de las ciencias como una sociedad viva, biológica, en la que los científicos interactúan no sólo de forma jerárquica, sino también mediante procesos de cooperación y competencia horizontales. Todo ello apoya diversas consideraciones sobre la educación, la política y la geografía científicas. (Autor)

Palabras clave: Vida Artificial. Sociología de la Ciencia. Teoría de la información.

\subsection{Abstract}

This paper intends to establish a connection between knowledge processes in the lower level of living societies - bacteria - and the modern sophisticated society of scientists from the perspective of the "artificial life" paradigm. Firstly, the living bacteria societies are explored from an informational perspective. Finally, the society of sciences is seen as a living biological society, where sciences interact not only hierarchically but in horizontal co-operation and competence processes. All of it leads the author to offer some considerations on the educative system, scientific politics and the Geography of Science. (Author)

Keywords: Artificial Life. Sociology of Science. Information theory.

\section{Introducción}

¿Qué tienen de común la bacteria, los sistemas nerviosos, los robots autónomos y la acumulación de conocimiento que se realiza en nuestro sistema cientí-

Scire. 1 : 1 (en.-jun. 1995). 
fico? Aparentemente muy poco; no parece que compartan sino los meros rasgos físicos derivados de su composición matérica, que incluso alguno podrá poner en tela de juicio para el último caso (¿cual es realmente la "materia" del conocimiento?). Pero, como vamos a argumentar aquí, hay un punto de vista nuevo que se está gestando en el movimiento científico de los últimos años, desde el cual la pregunta resulta pertinente. Y no sólo eso, quizás se trata de una de las preguntas más interesantes que cabe hacer dentro de ese complejo y heterogéneo campo multidisciplinar que parece estar cogiendo el relevo como vanguardia científica a la Inteligencia Artificial. Nos referimos (aunque no sólo a ella) a lo que se conoce como "Vida Artificial" (o "Artificial Life"; véase Langton, 1989; Langton et al., 1991).

Sin embargo, como vamos a ver, la cuestión que estamos indagando acerca de los rasgos comunes entre sistemas informacionales tan dispares no se agota en la posible confrontación y relevo entre esos dos campos interdisciplinares artificiales, que por otro lado están llenos de relaciones mutuas. Otras posibilidades conceptuales, que podrían resultar más adecuadas, se vislumbran alrededor de una nueva articulación de los propios conceptos biológicos y computacionales (un punto de vista informacional, al que aludiremos luego).

Acercándonos de una manera menos "artificial" y más "vital" a la cuestión que nos ocupa, atendamos a dejarla establecida en su formulación más general. Postulamos aquí que la acumulación de una información de carácter especial relacionada con el medio ("conocimiento") aparece como sustancial para una serie de sistemas que, directa o indirectamente, comparten propiedades características de la vida. Dicho con otras palabras, el origen y desarrollo de la vida, "natural" o "artificial", implica una relación fundamental para con el conocimiento. Y eso ha sido así desde el principio: desde las bacterias primordiales que aparecieron en nuestro planeta hace más de tres mil millones de años, a los robots "insectoides" de la primera generación de "Artificial Life", que han intentado emular las capacidades cognitivas de los animales más sencillos (Brooks, 1986).

La postura que aquí se va a defender no es original en cuanto a la búsqueda de relaciones comunes entre células, sistemas nerviosos y robots autónomos (común a diversos autores de artificial life y biología teórica). Sí que lo es en cuanto a postular que la célula más sencilla, la procariota, sirva como paradigma para las dinámicas inteligentes (o "intelectivas") en la relación que establece un sistema autónomo con su medio. También es original en cuanto a la necesidad de extender el análisis, como otro sistema autónomo más, al conocimiento que va elaborando el propio sistema científico.

Respecto a la actividad científica en sí, se va postular aquí que una de las características más destacadas de la ciencia es la de estar sirviendo como "senso-

Scire. 1 : 1 (en.-jun. 1995). 
rium" del organismo social. De ahí que, al igual que en los sistemas nerviosos y los robots autónomos, el más importante problema no sea el de reducir las facetas sensoriales entre sí, de acuerdo con algún principo jerárquico prefijado (como ha pretendido tradicionalmente el reduccionismo fisicalista), sino el de integrarlas adecuadamente de cara a una acción coherente, de cara a armonizar la vida del organismo social. Los conceptos informacionales - ¿vamos hacia la constitución de una genuina "ciencia de la información"?_ podrían tener ahí un protagonismo sustancial.

\section{Conflicto de paradigmas: Crítica a la Inteligencia Artificial. Algunas nuevas ideas computacionales y filosóficas}

2.1. Puede parecer extraño que para avanzar estas ideas necesitemos de entrada criticar, y quizás dejar de lado, los paradigmas contemporáneos de Inteligencia Artificial, que tan caros han sido, hasta muy recientemente, para diversas áreas de las neurociencias, psicología cognitiva, linguística, epistemología, etc. Quizá, pensando particularmente en el estudioso de la biblioteconomía, puede ser una gran tentación el usar como paradigma teórico las conceptualizaciones derivadas de una de las más modernas herramientas de trabajo que tiene a su alcance, a saber, los conceptos y sistemas de la Inteligencia Artificial. Pero es el caso que para obtener una panorámica general de la naturaleza de la inteligencia (del procesamiento de la información del que emerge la "inteligencia"), las construcciones de la IA ya no constituyen un asidero conceptual excesivamente fiable.

El sistema experto, las redes semánticas, los marcos y guiones ("frames" y "scripts", respectivamente), e incluso el procesamiento ligado a la robótica convencional estarían basados en lo que se denomina "representación del conocimiento" (junto a una visión exclusiva de la computación como "procesamiento de símbolos", de la que se derivan la separación hardware- software y la idea de "programa"). Por eso mismo han sido puestos globalmente en tela de juicio en cuanto a su validez como paradigmas generales de la inteligencia y las dinámicas cognitivas (Winograd y Flores, 1986; Beer, 1990; Brooks, 1991; Varela et al. 1991). Como señalan estos autores, la AI convencional, a partir de su misma aparición a mediados de los 50, se ha despreocupado de la historia biológica y evolutiva de la inteligencia, considerándola como un fenómeno reducido a la esfera humano-tecnológica. Se le ha atribuido además a la inteligencia un carácter casi exclusivamente lógico, "incorpóreo" y formalista (dejando como residuo intratable todo lo demás, especialmente ese procesamiento de "bajo nivel" que constituye el llamado sentido común). Tales características de antropocentrismo y logicismo, junto a lo que acabamos de comentar acerca de la computación como procesamiento de símbolos, la representación del conocimiento y la idea de pro-

Scire. 1 : 1 (en.-jun. 1995). 
grama, se han configurado como un paradigma central para la mayor parte de escuelas y disciplinas relacionadas con lo cognitivo durante las dos pasadas décadas.

Pero hoy día la validez de la IA como empresa científica de conjunto para el fenómeno de la inteligencia - y no sus realizaciones tecnológicas - está siendo cuestionada, y no son pocos los que la están abandonando como tal empresa científica. Al respecto, véase en la revista Science un reciente comentario sobre qué es lo que ha ocurrido finalmente con el que fue durante los 80 el programa estrella de la inteligencia artificial, el famoso proyecto japonés "Quinta Generación". Sin pena ni gloria, se le ha dado por concluido a mediados de 1992 (ver Yonezawa, 1992) sin haber alcanzado prácticamente ninguno de sus ambiciosos objetivos iniciales. Significativamente, su programa sustituto, bastante más modesto y, a la vez, quizá bastante más interesante científicamente, lleva por título "Real World Computing". Así pues, como una interesante rama de la "industria de la computación" nadie discute el interés histórico y tecnológico que ha tenido la IA; como acercamiento científico plausible a la cognición humana, y no digamos a la biológica, quizá cada vez son menos los que la defienden.

2.2. Actualmente, al pretender desarrollar modelos más amplios de procesamiento, tanto artificial como biológico, se está viendo - y quizá pagando- el carácter excesivamente parcializado de la IA, su exclusión del dominio de reflexión de grandes regiones de fenómenos que no encajaban con sus restrictivos puntos de vista. No se trata tan sólo de que los nuevos modelos de "computación emergente" a que aludiremos luego (redes neuronales, algoritmos genéticos, autómatas celulares, redes de enzimas, etc). hayan descabalgado buena parte de la visión computacional estricta de la IA; sino que el problema ha tenido también repercusiones y raíces más hondas en otras áreas del sistema de las ciencias y del conocimiento en general. Podríamos decir que, siguiendo las huellas del positivismo lógico, y llevando a su climax las posturas formalistas de éste, se ha estado promoviendo una visión del "mapa de las ciencias" excesivamente sesgada y que, paradójicamente para con su pretendido racionalismo, todas estas visiones abiológicas y logicistas han fomentado una considerable irracionalidad en el pensamiento científico relacionado con la inteligencia. Han insistido en un esquema de las disciplinas ordenado y jerarquizado, que pone un mayor énfasis en la "reducción" mutua de las ciencias y que desemboca en una física matematizada como base y paradigma de todas ellas. Mientras que, como adelántabamos en la Introducción, el problema factual de todos los sistemas cognitivos es la integración del conocimiento.

Los nuevos puntos de vista que están emergiendo sólo han podido avanzar muy relativamente en las cuestiones dejadas de lado. La densa interconexión de estos temas con las más variadas disciplinas científicas actúa como un poderoso

Scire. 1 : 1 (en.-jun. 1995). 
disuasor y obstaculiza el avance (y ello por dos motivos elementales: primero por la propia complejidad de la reflexión, y segundo por el permanente estado de precariedad en que se mantiene a los estudios interdisciplinarios en la ciencia contemporánea). Es curioso atender a la casi inextricable mezcla interdisciplinaria a que se ven forzados los autores que abordan estos temas (véase p.ej. Maturana y Varela, 1987; Brooks, 1991; Varela et al., 1991; Marijuán y Westley 1992). Que un autor pionero del campo de la robótica como es Brooks haya de relacionar sus críticas a la IA no sólo con la arquitectura de los ordenadores, sino también con la neurobiología, la etología, la psicología cognitiva, la sociología, la filosofía, etc., es una muestra pragmática de la densa raíz multidisciplinar de estas cuestiones.

2.3. De alguna manera, los nuevos puntos de vista parten todos ellos de que en lo que se refiere al conocimiento no estamos solos. Si de momento dejamos de lado los espectaculares robots autónomos de la Artificial Life, nos encontramos frente a tres sistemas peculiares de matriz biológica que claramente almacenan "conocimiento". Nos referimos a la célula procariota (la bacteria), al sistema nervioso, y a la propia producción de conocimiento de la sociedad humana. Como ya hemos adelantado, los nuevos puntos de vista han puesto en el centro mismo del debate la complejidad y la corporeidad, tanto del ambiente como de la propia entidad cognitiva. Se trata de entidades cuya "inteligencia" ha de ser estudiada en relación con el mundo real, en el verdadero ambiente que las rodea, y no en un mundo extremadamente simplificado situado en el espacio virtual de un ordenador. La corporeidad de la propia entidad cognitiva no puede ser desatendida a la hora de analizar sus características informacionales, a la hora de establecer su arquitectura de procesamiento informacional; muy al contrario, no parece que se pueda legitimar aquí la separación hardware-software en que se basan la idea de programa y de incorporeidad. En concreto respecto a la corporeidad, uno de los rasgos más importantes a resaltar, quizá el rasgo crucial, es el carácter de "sociedad" que muestran las tres entidades que comentamos. Respectivamente podríamos denominarlas: "la sociedad de las enzimas", "la sociedad de las neuronas" y la "sociedad de los científicos" (o ésta última, más en general, la "sociedad de los individuos"). Estamos, con otras palabras, diciendo que son las "sociedades" las que necesitan —y saben— acumular conocimiento, bien endógenamente o exógenamente...

Pero aparte de la estructura social per se de estas entidades, habría otras dos razones importantes para haber introducido el término "sociedad" en nuestro análisis, una computacional, la otra filosófica.

En lo que toca a lo computacional, detrás de este término hay una idea no convencional de computación, que va más allá de la arquitectura serial von Neumann de la inmensa mayoría de los ordenadores actuales (arquitectura que es

Scire. $1: 1$ (en.-jun. 1995). 
el sustrato natural de la inteligencia artificial), y también de lo que parece ser su complemento, las arquitecturas de procesamiento en paralelo. Entre otras nuevas ideas computacionales, en el área de artificial life se ha acuñado lo que se denomina computación emergente (Forrest, 1990; Fayne, 1990). Se trata de un tipo de computación efectuado mediante "enjambres" o "sociedades" de "agentes" elementales, en que las propiedades computacionales emergen como resultado global de la interconexión de las acciones individuales que los agentes llevan a cabo simultáneamente. Así, de multitud de fenómenos a nivel local emergen pautas coherentes a un nivel macroscópico que pueden ser canalizadas hacia el procesamiento de fenómenos de ese mismo nivel. Ejemplos inmediatos de esta computación emergente son las redes neuronales en general, los algoritmos genéticos, los autómatas celulares, las redes inmunológicas y también los modelos de las interacciones de comportamientos en algunas de las sociedades animales más elementales. En una línea parecida, otro autor que ha desarrollado el carácter "socio-emergente" de las redes computacionales, común a los sistemas biológicos, es B.A. Huberman $(1988,1992)$. Su planteamiento es el de una "ecología computacional" que permite la asignación de funciones y recursos en la cooperación de ordenadores individuales a través de redes... Por otro lado, la "computación molecular", desarrollada entre otros por M. Conrad (1990, 1992), se centra en el procesamiento de la información que pueden llevar a cabo las redes de enzimas; es curioso que el núcleo de este procesamiento enzimático resulte de una acumulación de efectos cuánticos, no-formalizables por definición (no puede ser extraído por tanto un "programa" separable), que se están produciendo entre las enzimas y sus sustratos ( $i y$ de ahí deriva precisamente la especial potencia computacional de las enzimas!)

2.4. La otra razón para usar el término "sociedad" es filosófica. Su desarrollo nos va a devolver, en parte, a la crítica de la inteligencia artificial esbozada en el apartado 2.1. Inicialmente, el uso especial de este término se debe al filósofo A.N. Whitehead (en su etapa posterior al positivismo lógico). Tras una estrecha colaboración en el campo matemático y filosófico con Bertrand Russell, Whitehead fue derivando paulatinamente hacia una avanzada filosofía organicista, postulando "sociedades" constituidas por "redes de procesos" que resultaban en ocasiones experienciales en que prevalecían unas u otras reglas de cambio. Junto a Whitehead, se habría de citar a J. Ortega y Gasset. Los méritos de su "perspectivismo" y de su peculiar versión del "racio-vitalismo" quizás podemos apreciarlos mejor ahora, a la luz de los debates actuales, que cuando fueron propuestas dos generaciones atrás. Ortega alcanza su máxima clarividencia cuando analiza los problemas inherentes a la división de funciones en el seno de las comunidades científicas —el tema del "especialismo". Nos viene a decir que la organización de la propia comunidad científica, la evolución de su corporeidad

Scire. $1: 1$ (en.-jun. 1995). 
institucional y de sus pautas internas de división del trabajo, son factores fundamentales en la producción de conocimiento, pero como regla general la visión racionalista los ha dejado fuera del análisis.

En los debates filosóficos que están acompañando la demarcación de fronteras intelectuales entre la inteligencia artificial y la vida artificial se ha vuelto, en parte, a la situación de partida: a las escuelas filosóficas que en los años 30 se desmarcaban del excesivo formalismo del positivismo lógico. Aparte de la referencia que aquí hemos hecho a Whitehead y Ortega, algunas corrientes influyentes de artificial life se han acercado a la fenomenología (Husserl, Merleau- Ponty) y la hermenéutica (Heidegger). Es decir, las filosofias europeas por excelencia de hace una o dos generaciones, más o menos cercanas al idealismo, están ahora teniendo un papel importante en contribuir a recentrar las ideas computacionales que el positivismo lógico anglo-americano sesgó en exceso cuando estableció el paradigma de la inteligencia artificial. (No sólo ideas filosóficas más o menos elaboradas de la tradición europea están interviniendo en el debate, véase en Varela et al. 1991, una seria defensa del papel del pensamiento oriental, concretamente la tradición budista hindú, para contribuir a iluminar estas cuestiones).

En suma, desde una pluralidad de puntos de vista se nos está llevando a considerar una concepción del conocimiento y la inteligencia distinta a la logicista. El conocimiento, se nos viene a decir, es la información especial que algunas "sociedades computacionales" pueden acumular, en su propio interior o bien externamente, para poder resolver los problemas que les presenta su medio. Concretamente, lo que el presente autor ha defendido, junto con John Westley, es que en todo ese mundo de relaciones, analogías, metáforas, etc., que cabe establecer entre las diversas "sociedades" potencialmente basadas en el conocimiento, hay un sistema que puede resultar central para avanzar en la elaboración intelectual de estos temas. Es la célula viva, y particularmente la más simple (la célula procariota, la bacteria), la que parece se puede configurar como "sociedad clave" para avanzar en la explicación de ese tupido mundo de interrelaciones que caracteriza a los sistemas basados en conocimiento. Será el tema que desarrollaremos en el siguiente capítulo.

La bacteria es de entrada la entidad que nos proporciona las pistas más claras para diferenciar fácilmente entre conocimiento e información. El conocimiento es información de un carácter especial: información con "historia", que ha sido experimentada, probada, etc., y que incorporada al sistema se traduce en una acción posterior coherente con la dinámica del propio sistema. Esa es la manera en que hay que contemplar los genes que la bacteria acumula en su genoma: contienen una enorme cantidad de información respecto al propio sistema y a su ambiente que ha sido verificada y contrastada a lo largo de incontables generaciones. La diferencia, para con la información a secas, es que ésta consiste en

Scire. $1: 1$ (en.-jun. 1995). 
algo mucho más bruto e inmediato: información es cualquier cosa, cualquier cambio o dinámica que incide en el sistema y que cambia el estado de éste - lo único que implica es un cierto "procesamiento" por parte del sistema. Basta que el sistema se dé cuenta de algún fenómeno respecto a un fondo preexistente, para que ya exista como información para ese sistema ("darse cuenta" implica ya un procesamiento elemental). Anotemos ahí que la información, al igual que el conocimiento, ha de estar siempre referida, implícita o explícitamente, a la entidad de mayor dimensión con la que interacciona, a su sistema "procesador".

\section{Bosquejo informacional de la célula procariota}

3.1. El mundo de las células procariotas, tal y como W.I. Thompson (1989) lo considera, constituye un microcosmos en que simbólicamente se reflejan numerosos fenómenos del mundo que nos rodea, y muy en especial los rasgos más arquetípicos de nuestros sistemas sociales de conocimiento. La argumentación de ese autor, en buena parte literaria, va a recibir aquí un desarrollo casi paralelo desde los campos biológico y computacional.

De entrada, hay que decir que si la bacteria (o para el caso, cualquier célula viva) fuera un reciente desarrollo de las nanotecnologías computacionales, en vez de tratarse de una entidad natural, previsiblemente tendríamos que agotar toda la gama de superlativos a la hora de describirlas. Como vamos a ver dentro de poco, en tan sólo una micra cúbica estos seres vivos encierran un mundo de procesos computacionales "moleculares" tan sofisticados que, cuantitativa y cualitativamente, desbordan cualquier estimativa simplista de los bits que pueda tener ese sistema o cualquier comparación con el hardware de los ordenadores convencionales.

El papel que las propias bacterias han jugado en el desarrollo del pensamiento biológico moderno es ya revelador de su singularidad. La bacteria, la más sencilla de las células vivas autónomas (excluimos los viroides, virus, plásmidos, etc)., fue considerada por los biólogos del siglo XIX, e incluso de principios del XX, poco menos que como un estorbo (Shapiro, 1988). De hecho su estudio corrió a cuenta de patólogos (médicos), más procupados por las enfermedades que producían que por las propiedades biológicas de ellas mismas. Incluso Pasteur, el pionero de su estudio, fue expulsado de la profesión médica por colegas enfurecidos de que prestara su atención a seres vivos "imaginarios", que contradecían el pensamiento de la época acerca de la causa de las enfermedades y la generación espontánea de la materia viva. Tras ser reconocida su existencia, la importancia de las bacterias en la biología fue aumentando progresivamente, hasta que con la aparición de la biología molecular en los años 50 llegaron a convertirse en elementos centrales de trabajo en numerosas ramas teóricas y experimentales de la biología contemporánea.

Scire. 1 : 1 (en.-jun. 1995). 
Hoy día sabemos que, aparte de producirnos enfermedades, las bacterias (o "procariotas", células que carecen de núcleo) resultan fundamentales para los ecosistemas de suelos, mares y atmósfera. Ellas introdujeron el oxígeno en la atmósfera terrestre, lo que hizo posible la evolución de otros unicelulares hacia la multicelularidad y más tarde la aparición de sistemas nerviosos; produjeron también diversos minerales y combustibles fósiles de gran importancia económica (y siguen trabajando para nosotros en multitud de procesos industriales relacionados con la fermentación). Sabemos igualmente que la integración de varias especies de bacterias es lo que originó la célula con núcleo ("eucariota"), que fue la que evolucionó hacia los animales y plantas superiores (Margulis, 1970). Resulta simbólico que las bacterias sigan dentro de nosotros, tanto en la flora del tubo digestivo de todo los vertebrados como en las mitocondrias y flagelos del interior de cada célula (Margulis, 1982).

3.2. $\mathrm{Si}$, suponiendo que se tratara de un producto de las nuevas tecnologías computacionales, procediéramos a "desmontar" el sistema de la bacteria encontraríamos, de fuera a dentro, lo siguiente:

- una membrana,

— una red de 300 a 500 reacciones químicas distintas,

— una población de varios millones de enzimas y proteínas de unos dos mil tipos distintos, la célula),

— una hebra de ADN enormemente larga (unas dos mil veces el diámetro de

— así como diversas moléculas de ARN, fosfolípidos, azúcares, iones, etc.

¿De qué componentes provienen básicamente las propiedades tan formidables que tienen estos sistemas? Atendamos a que no sólo tendríamos que explicar características evolutivas generales como las arriba comentadas, sino además comportamientos netamente "informacionales" que son fácilmente observables con los modernos medios de laboratorio, tales como: diferenciación y reconocimiento sexual, movimiento mediante motores rotatorios, sistemas de orientación respecto a diversas variables físicas, detección de gradientes químicos, formación de colonias y agregados multicelulares, integración metabólica inter-especies... (véase Shapiro, 1988; Sonea, 1990; Marijuán 1991)

Abreviando el análisis de los distintos componentes, daremos por sentado que las propiedades fundamentales de este sistema celular provienen de lo que antes hemos denominado "sociedad de las enzimas". Son éstas las entidades individuales que detentan la capacidad de acción en el sistema. Cada enzima o proteína es capaz de controlar reacciones químicas específicas, de integrar la información de diversas variables físico-químicas, de hacer operaciones individuales de

Scire. $1: 1$ (en.-jun. 1995). 
corte, alargamiento y unión de diversos polímeros, de unirse a otras moléculas para formar agregados y microestructuras, de integrarse en los más variados desarrollos inter- e intra-celulares, etc. Asímismo son estas moléculas las que se sitúan en la membrana de la célula para constituir los receptores y proteínas canal que comunican al interior de la célula con su medio externo.

No es de extrañar, pues, que según se fueron conociendo las propiedades de las enzimas y proteínas, y cómo la célula procedía de una forma perfectamente regulada a la síntesis de las mismas, numerosos autores se refirieran explícitamente al papel crucial que como "procesadores de la información" tenían esas sustancias dentro del sistema celular (para una recopilación de autores clásicos véase Marijuán, 1991). Por ejemplo F. Jacob (1970) escribe: "las proteínas están capacitadas para "palpar" en cierto modo a las especies químicas, "sondear" la composición del medio y "preveer" los distintos estímulos específicos... detentan el saber necesario para mantener la organización de la célula... En torno a estas proteínas se ordenan los circuitos de regulación. Como en electrónica..."

La comparación que hace Jacob con la electrónica sobrepasa la mera metáfora (también J. Monod, en su célebre obra "El azar y la necesidad", publicada el mismo año que la de Jacob, compara a las enzimas con los relés y los transistores electrónicos). De hecho, las ecuaciones que controlan la dinámica química de una enzima pueden ser expresadas mediante una función "binaria" similar a la del transistor, o mejor aún, igual que las funciones lógicas que contienen los modernos microcircuitos o chips (Conrad, 1990; Marijuán, 1991; Marijuán y Westley, 1992). Si luego atendemos al hecho de que las enzimas están todas conectadas entre sí, tanto por medio de la red de reacciones químicas sobre las que actúan, como por otra compleja red superpuesta de "activaciones" e "inhibiciones" mutuas (gracias a las sustancias de control conocidas como "efectores"), el resultado es que emerge una red global enormemente compleja de "procesamiento social".

Las propiedades primarias de esta red global corresponden a lo que se denomina "autoorganización" — el sistema es capaz de responder a variaciones moderadas del medio y de organizarse por sí mismo, manteniendo una distribución coherente de las concentraciones, velocidades de reacción, etc. Se considera que existe un limitado número de "atractores" hacia los que tiende el estado del sistema: ante cualquier pequeña variación en alguna de las entradas, o en las concentraciones intermedias, el sistema será capaz de volver hacia el estado inicial y de dar una respuesta en que tiende a optimizar la energía química global.

3.3. Pero el mundo del $A D N$ da algo más a la célula. Aparece una propiedad radicalmente diferente de la autoorganización. Analicemos la bacteria antes y después del contacto con una sustancia nutritiva como la lactosa, o simplemente

Scire. 1 : 1 (en.-jun. 1995). 
tras calentarla moderadamente. La población de enzimas presentes habrá cambiado dramáticamente: se habrá disparado la producción de las enzimas codificadas en lo que se conoce como "operón de la lactosa", o habrán sido activadas las docenas de genes que integran la respuesta al "shock térmico". En ambos casos la célula es radicalmente distinta a lo que era hace dos o tres minutos, tiene una nueva población de enzimas, e indudablemente está mucho mejor adaptada a las nuevas condiciones del medio. (No deja de ser similar a lo que ocurre en una sociedad humana, que cuando, digamos, se descubre oro o petróleo en una región, la cantidad y tipo de individuos y actividades cambian dramáticamente; o también es similar a lo que ocurre en la disposición espacial y funciones internas de las células de un animal, tras haber detectado su sistema nervioso determinadas informaciones del medio). Atendamos a que la emergencia de esta nueva propiedad de "auto-modificación", genuinamente biológica, se produce inicialmente en la célula, y ello porque la "sociedad de enzimas" es capaz de manejar un mundo de ADN que permite modificar la propia población de enzimas de una manera acorde con los cambios internos y del medio.

La propiedad biológica de la automodificación permite una visión diferente del fenómeno de la inteligencia biológica. El ser vivo es un sistema dotado de inteligencia porque es capaz de acumular en su interior información de carácter especial que le permite desarrollar dinámicas de automodificación, y no por propiedades metafísicas ocultas que queramos buscar en ellos (como históricamente pretendió el "vitalismo", al principio de nuestro siglo). Es obvio que los campeones en el avance de esta propiedad van a ser luego los sistemas nerviosos de los animales avanzados, y muy especialmente el caso humano, con los dominios casi infinitos de constructividad y modificabilidad que permiten los lenguajes, la escritura y otras invenciones similares.

Así pues, las metadinámicas que muestra la bacteria nos permiten considerar la enorme red binaria de sus enzimas, conectadas a los depósitos de información del ADN, como si constituyeran un ordenador capaz en un momento dado de "tirar a la papelera" la mitad de su hardware y (su software asociado) y de sacar otro nuevo en escasos minutos. De ahí que el sistema pueda mostrar todas esas (increibles) propiedades generales externas e internas que comentábamos antes... porque dispone de una poderosa red computacional de enzimas y ADN que está especializada en resolver los más complejos problemas de la "vida bacteriana"incluso, como ha estudiado Sonea, los más difíciles problemas de vida en común entre especies completamente diferentes.

3.4. La evolución posterior de determinadas comunidades de células procariotas abrió paso a las células eucariotas, y con estas el mundo del ADN adquirió, si cabe, una mayor relevancia en la vida celular. Es curioso atender a las transformaciones sobrevenidas:

Scire. $1: 1$ (en.-jun. 1995). 
- Primero, la acumulación de información, de genes, alcanza un nivel de 10 a 100 veces superior, y se hace necesario encerrar tan enorme "biblioteca" en un recinto especializado, el núcleo.

- Segundo, aparecen unas proteínas especiales, las histonas, que permiten un notable ahorro de espacio en el empaquetamiento del ADN; se produce también la regionalización del ADN en cromosomas.

- Tercero, gracias a los dos puntos anteriores se hace posible organizar nuevos modos de controlar la expresión de los genes, así como inaugurar un procesamiento más flexible y sofisticado en la transcripción del ADN a ARN (la eliminación selectiva de los "intrones" en el ARN, lo que permite interpretar la información de un mismo gen de varias maneras distintas).

- Cuarto, algunos bloques constitutivos de la célula eucariota retienen parte de su ADN (las mitocondrias y los cloroplastos) y desarrollan una vida semiautónoma, cumpliendo funciones especializadas, en el ecosistema interno de la célula.

- Quinto, las células eucariotas, gracias al punto anterior, adquieren una potencia energética suplementaria que, aunada a su nuevo poder computacional, permiten la organización de sofisticadas funciones tanto colectivas como individuales de una gran potencia y complejidad; piénsese en la contracción de la célula muscular, o en la computación de las neuronas y del sistema inmunitario... y atiéndase también a que, partiendo de un único genoma, un mamífero avanzado es capaz de desarrollar cerca de 300 tipos de células diferentes en su organismo.

Lo más importante a considerar es que, a lo largo de su evolución, la célula mantiene su "corazón computacional" intacto (una sociedad de enzimas automodificada por medio de un mundo de ADN), pero se las ingenia para introducir cambios dramáticos en la "arquitectura" de su sistema de automodificación, especialmente en la extensión y organización de su depósito informacional, su "acumulación de conocimiento". Cada gen viene a representar el equivalente a un invento tecnológico, o mejor, a un teorema o grupo de teoremas de una de nuestras disciplinas, conteniendo una información compleja que se corresponde detalladamente con algún aspecto del mundo externo o interno; información que ha sido contrastada "experimentalmente", que está lista para la acción y que es coherente con la información acumulada en los otros genes del sistema (conocimiento, pues). Así, el conjunto del genoma representa la acumulación total de conocimiento que a lo largo del proceso evolutivo ha protagonizado la célula. No resulta difícil inferir que es el crecimiento de la información acumulada, en respuesta a las nuevas exigencias del medio, lo que va demandando cambios radicales en la "arquitectura" de la propia información. Cambios que, en general, no se traducen en "eliminaciones" drásticas, sino en "invenciones" que se van super-

Scire. $1: 1$ (en.-jun. 1995). 
poniendo a las estructuras de las antiguas soluciones y les van atribuyendo nuevas funciones.

A este respecto, no cabe duda que la invención informacional más importante de los eucariotas multicelulares fueron los sistemas nerviosos, la "sociedad de las neuronas". Ese será nuestro objeto en el siguiente capitulo.

\section{De los sistemas nerviosos a las sociedades}

4.1. Los sistemas nerviosos constituyen el paradigma por antonomasia de procesamiento de la información en los sistemas biológicos. En la historia de su estudio científico podríamos apuntar a un desarrollo hasta cierto punto paralelo con los estudios sobre las células procariotas; no cabe duda ahí que Cajal ha sido el Pasteur de la neurobiología. Pero a diferencia de las células procariotas, que ya nos han entregado muchos de sus más importantes secretos, el gran problema de las neurociencias permanece aún sin resolver: se trata del problema de la memoria. ¿Cómo se almacena la información en la "sociedad de las neuronas"? Y todavía más difícil, ¿cómo son capaces las neuronas de modular sus acumulaciones de información para poder construir "conocimiento" fidedigno acerca del medio externo?

Aparte del genoma de cada neurona (que hoy día ya sabemos con toda seguridad que no puede ser usado para almacenar la información que constituye la memoria cerebral, como algunos científicos habían preconizado en los años 60), multitud de evidencias científicas apuntan a que son las redes de sinapsis las que funcionan como depósito informacional. La capacidad para "ajustar" la conductividad relativa de las sinapsis en la transmisión de los potenciales eléctricos entre neuronas distintas parece que es lo que permite la acumulación de información y la emergencia de un nuevo tipo de procesos de automodificación. Las redes neurales artificiales, basadas en sinapsis ajustables, hasta cierto punto permiten corroborar esta hipótesis (pero las diferencias con las redes neuronales biológicas son demasiado importantes como para que puedan servir de modelo).

La dinámica colectiva que tiene lugar en la "sociedad de las neuronas" es mucho más sofisticada, y sobre todo mucho más rápida, que la que hemos visto antes para la célula aislada. Ello no quiere decir que los fenómenos enzimáticos y químicos estén excluidos de la nueva dinámica eléctrica de las neuronas (al revés, la nueva dinámica y metadinámica eléctrica está basada toda ella en propiedades "antiguas" químicas de la célula), sino que el nuevo procesamiento asociativo inter-celular desarrolla unas propiedades computacionales realmente notables en cuanto a velocidad, organización de la memoria, procesamiento de señales, reconocimiento de pautas, integración de procesos heterogéneos, etc., que en sí suponen una radical innovación respecto al tipo de procesos informa-

Scire. 1 : 1 (en.-jun. 1995). 
cionales que caracterizan a la célula aislada.

4.2. El origen y evolución de los sistemas nerviosos permite aclarar, hasta cierto punto, el papel de la célula individual dentro de la red neuronal colectiva y su peculiar adaptación a la misma. Durante la década de los 60 y principios de los 70 tuvo lugar una interesante polémica acerca de cuales habían sido las primeras especies en desarrollar un verdadero sistema nervioso. Científicos todavía en activo, como Mackie, Ceccaty, Horridge, Bullock, etc., argumentaron acerca de las nuevas características morfológicas y bioquímicas que el microscopio electrónico y otros hallazgos recientes de aquel tiempo permitían apreciar por vez primera en los sistemas nerviosos de las especies menos evolucionadas. Tras numerosas discusiones, los celentéreos (particularmente los Cnidaria) batieron a los Espongiaria (particularmente a las esponjas Hexactinélida). Y el defensor a ultranza del carácter neuronal de determinadas células de las esponjas, el neurobiólogo francés Max Pavans de Ceccatty, tuvo que reconocer finalmente la mayor plausibilidad de los puntos de vista contrarios (Ceccatty, 1973). Lo más interesante, para lo que aquí comentamos, es que quedó claramente establecido que las neuronas son en su origen células asistenciales "tróficas", mensajeras (para esa función desarrollan inicialmente su "largo brazo", para llevar sustancias y señales en propia mano a otras células sin interferir con las intermedias); posteriormente empiezan a hacer un uso accidental de la electricidad, que luego resultará cada vez más genaralizado y sofisticado. Con la progresiva diferenciación de las neuronas, y su especialización en la nueva función eléctrico-informacional, se va formando una barroca combinación de mecanismos y compuestos de diverso origen, bacterianos y eucariotas, antiguos y modernos. El "correo manual" queda firmemente integrado con su homónimo "electrónico", y las funciones de la neurona proceden a mezclar lo más moderno con lo más antiguo.

Lo realmente curioso de esa mezcla es que algunas de las propiedades más avanzadas del procesamiento neuronal han recogido elementos arcaicos y les han dado nuevos e inesperados roles. Tal es el caso, descubierto a principios de los 80 , de diversos neuropéptidos relacionados con sensaciones placenteras y dolorosas de la corteza límbica (las "endorfinas", que intervienen decisivamente en el fenómeno social de la drogadicción), que se ha comprobado funcionan también en las bacterias con fines comunicativos dentro de su metabolismo interno (Le Roith et al., 1984). Es decir, en uno de los mecanismos cerebrales de los mamíferos que resulta más importante para la adaptación al medio encontramos un uso accidental de una sustancia comunicadora ya usada por las bacterias; sustancia que también algunas plantas han heredado desde los mismos ancestros bacterianos, destinándola luego a sus propias funciones internas de comunicación. El resultado de esa sustancia compartida evolutivamente por plantas y mamíferos es que la ingestión de los opiáceos de las plantas altera por completo los equilibrios

Scire. 1 : 1 (en.-jun. 1995). 
entre nuestros propios neurotransmisores, y por ende desorganiza los procesos cognitivas y emocionales.

Algunos autores han sugerido que en la memoria pueden aparecer también algunas de las relaciones tróficas antiguas. Eso es lo que plantea, por ejemplo, la teoría trófica de D. Purves (1988), y muy particularmente la teoría dual de J.K. Collins (1991), teoría esta última que intenta integrar en un esquema coherente los aspectos más importantes de la dinámica cerebral: anatomía, procesamiento, organización en supersistemas, memoria, fenómenos tróficos, desarrollo, etc. De hecho, los postulados de este autor pueden suponer una auténtica revisión conceptual de la neurociencia cognitiva y, si llegan a ser validados experimentalmente, implicarían una manera radicalmente distinta de entender los aspectos básicos del procesamiento cerebral, muy en especial cómo está organizada la obtención de "conocimiento" significativo biológicamente por parte del sistema nervioso central.

4.3. En suma, el sistema nervioso ha quedado establecido evolutivamente como si fuera una red neuronal artificial, pero de procesamiento "heterogéneo", con múltiples tipos de neuronas, y con increibles propiedades individuales de las mismas y de sus sinapsis —empezando por el viaje "iniciático" migratorio que muchas de las células nerviosas han de desarrollar durante la embriogénesis, que envuelve el desplazamiento de grandes distancias (relativamente), así como el crecimiento y elongación del axón y las dendritas, y el establecimiento de determinadas sinapsis con una total precisión. La pasada década ha traído el conocimiento de la base molecular de muchos de estos fenómenos.

Lo mismo que en la transición de las células procariotas a las eucariotas, en la evolución de los sistemas nerviosos encontramos con toda claridad una serie de fenómenos singulares de "evolución de arquitecturas informacionales". Muy esquemáticamente, de la red difusa de los celentéreos se pasa a la organización en redes de ganglios de los invertebrados inferiores, luego a los ganglios cerebroideos y a los cordones corporales, al cordón dorsal de los procordados, a la aparición del córtex en el tele-encéfalo de los vertebrados, y a la acumulación de capas y más capas en el techo del mismo (en los peces, anfibios, reptiles, aves y mamíferos), llegando por fin al enorme neocórtex de los primates y los delfines, y al singular caso humano... Paralelamente, cada vez se va registrando una mayor sofisticación en el procesamiento informacional, y los animales pueden disponer de una capacidad creciente para acumular conocimiento respecto a su medio. Lo cual les permite una menor dependencia respecto a los patrones "fijos" transmitidos genéticamente, y un mayor uso del conocimiento individualmente acumulado.

Es decir, los problemas del organismo — cómo desplazarse, qué comer, dón-

Scire. 1 : 1 (en.-jun. 1995). 
de cobijarse, esconderse, atacar, descansar, aparearse y criar, socializar, reconocer predadores y presas, etc. - se resuelven implicando cada vez una mayor cantidad de conocimiento neuronal especializado, "aprendido" y optimizado respecto a las colecciones de circunstancias concretas; en vez de respuestas ciegas frente a patrones estereotipados. Ese conocimiento aprendido ha podido ser acumulado (y obtenido) gracias a arquitecturas informacionales especiales que han sustentado el enorme crecimiento de la complejidad dinámica y metadinámica de la automodificación neuronal (Collins, 1991).

Una vez más, como decíamos al principio de este artículo, a lo largo de la evolución se nos hace transparente que el conocimiento —su acumulación-es fundamental en el desarrollo de la vida.

4.4. Respecto a los sistemas sociales humanos, hablar de conocimiento e información dentro de los mismos resulta obvio. Hemos llevado hasta límites insospechados las acumulaciones "externas" de conocimiento, y hemos llevado hasta límites insospechados el flujo de procesos informacionales relacionados con aquellas. Parece claro que en eso se basa la progresiva sofisticación de la especialización y división del trabajo en las sociedades modernas. Las sociedades han podido crecer en complejidad de procesos internos gracias, en primer lugar, a la acumulación de conocimiento protagonizada por las ciencias y las tecnologías ¿Cuántas profesiones tiene una sociedad contemporánea que no hayan sufrido la influencia de las ciencias? ¿Cuánto tiempo y esfuerzo intelectual requiere internalizar el conocimiento necesario para desempeñar esas profesiones? Hemos creado un sin fin de mecanismos e instituciones educativas para tutelar los procesos sociales de aprendizaje. En estos aspectos de especialización e instrucción de los individuos, la diferencia entre las sociedades contemporáneas y las primitivas es flagrante.

Pero hay que hacer una matización. Aunque las sociedades modernas estén basadas en acumulaciones grandiosas de conocimiento que, cómo no, han requerido la correspondiente evolución de arquitecturas informacionales especializadas (como las propias disciplinas), aunque históricamente esos mundos informacionales hayan estado basados (especialmente en lo que se refiere a la ciencia y tecnología) en invenciones sofisticadas como la escritura y la imprenta y en instituciones altamente autónomas, subsiste siempre un factor biológico "primitivo" que condiciona la evolución y "vida social" de todo el conglomerado socio-intelectual.

El concepto de "vida social" no es aquí una figura retórica. Si vivimos en sociedad, si se acepta el esquema de restricciones de ésta, es sólo en la medida que lo percibimos como favorable para continuar las operaciones vitales individuales. Estas, abstractamente, son las mismas operaciones generales de subsis-

Scire. 1 : 1 (en.-jun. 1995). 
tencia y reproducción que, recordémoslo, iniciaron nuestros antecesores bacterianos hace miles de millones de años, incluso con una maquinaria bioquímica basada ya en los mismos códigos y mecanismos. Son las mismas operaciones que otras muchas sociedades de vertebrados e invertebrados llevan a cabo secularmente en el seno de los ecosistemas naturales. Operaciones basadas en todos los casos en densas envolturas informacionales. Pero estamos acostumbrados a ver sólo las últimas envolturas culturales, inventadas socialmente, con que elaboramos y sofisticamos la vida mamífera básica. El análisis de McLuhan (1964) acerca de la información en las sociedades es quizá el ejemplo más palmario de no ver el "fondo vital" que anima perennemente a la sociedad humana, y que guía la evolución de sus formas y arquitecturas informacionales. Y a su respectivo nivel, ocurre algo muy parecido con la sociedad de las neuronas, y con la de las enzimas...

En la sociedad humana, al igual que el caso de las neuronas en un cerebro, se produce una curiosa persistencia de lo antiguo bacteriano — porque lo más antiguo resulta siempre lo ligado a la anterior vida independiente de los elementos constitutivos. Tanto en la sociedad como el cerebro, el comportamiento "trófico" ("antiguo") de las entidades individuales resulta de muchos modos crucial para el ordenamiento del sistema general, para el buen funcionamiento de sus funciones colectivas, para poder tener una capacidad acumulativa de conocimiento, y para ser capaz de usar el conocimento para adaptarse a los cambios.

Quizás el concepto de "derechos del individuo", la primacía de determinadas órbitas de acciones propias ligadas a la supervivencia y a la libre "intelección" del medio, no es sino una manera cultural del mundo occidental de expresar esta pervivencia de la autonomía biológica del individuo en el seno de la comunidad social: el derecho a la "felicidad mamífera" en el ecosistema artificial de las sociedades.

En definitiva, la complejidad social es inabordable — compárese el incremento dramático de complejidad que se produce al saltar de la función de la enzima a la función de una neurona, y de ésta a la de una persona desarrollando una actividad profesional. Los flujos informacionales que se establecen en las sociedades humanas, aun en los casos más sencillos, desbordan la capacidad analítica de las ciencias especializadas (incapaces todavía de abordar coherentemente la dinámica cognitiva que establece un único cerebro para con su medio). Nuestras ciencias sociales no han tenido otro remedio que encajar conceptos de una forma heurística, y con un resultado más o menos feliz, cubriendo las dinámicas informacionales más destacadas: y las hemos denominado Psicología, Sociología, Economía, Política, Antropología, Historia... pero todavía hemos sido incapaces de encontrar una aceptable definición multidisciplinar de qué es información. Al respecto, este enfoque que aquí seguimos, enraizado en las propiedades informa-

Scire. 1 : 1 (en.-jun. 1995). 
cionales del sistema celular, nos sugiere que muchas de las claves explicativas de las ciencias sociales hay que buscarlas preferentemente en las épocas de emergencia de la propia complejidad social a que se refieren. Las épocas transicionales en que se consolidan las formas emergentes de organización resultan decisivas. En ellas es como si se procesara una gran cantidad de información por parte del sistema social, quedando ésta cristalizada en forma de cambios, prácticamente irreversibles, en las arquitecturas y estructuras informacionales de la propia sociedad. Con ello las sociedades se van abriendo y cerrando a sí mismas toda una serie de posibilidades evolutivas...

El caso particular de las ciencias en las sociedades humanas vamos a verlo con más detalle en el siguiente capítulo.

\section{El sistema de las ciencias}

5.1. En este capítulo vamos a reflexionar acerca de la organización general de las disciplinas científicas, pero intentando abordarlas desde una perspectiva informacional. Primero de todo, necesitamos reflexionar brevemente acerca del tema informacional propiamente dicho. ¿Cómo avanzar en la consolidación de esa "perspectiva informacional" que tan frecuentemente hemos planteado? ¿Tiene suficiente realismo lo que apuntábamos en la Introducción acerca de una posible Ciencia de la Información?

Una respuesta formalista a esas dos preguntas no basta. En el fondo, lo que estamos preguntando se refiere a qué nuevas herramientas intelectuales tenemos a nuestra disposición, y qué factores son los que han renovado el planteamiento científico de estos problemas. Como apuntábamos en la Introducción, son los ordenadores (incluyendo ahí los robots autónomos), además del mundo de las células (desde las bacterias, a las neuronas y organismos), los objetos cuyo estudio ha variado radicalmente el panorama científico "informacional" de estos últimos años. Además, sus disciplinas centrales, la Ciencia de la Computación y la Biología Molecular, se han constituido como los principales focos que han revolucionado la ciencia en la segunda mitad del siglo XX.

Al respecto, Tom Stonier (1990) sostiene que el papel social y científico de los ordenadores guarda un marcado paralelo con lo que ocurrió hace dos siglos en el caso de las máquinas de vapor. Estas no solo propiciaron una revolución general industrial, económica y social, con el declive de unas clases e imperios y el ascenso de otros, sino también cambios científicos fundamentales. Unas dos generaciones más tarde de la definitiva extensión social de las máquinas de vapor, éstas dieron lugar al surgimiento de una nueva ciencia: la Termodinámica. Primero se produjo la experimentación técnica, luego vino la reflexión científica... esa parece ser la pauta general. También en el caso del reloj y la imprenta

Scire. 1 : 1 (en.-jun. 1995). 
hay un curioso paralelo histórico respecto a la difusión masiva de estas técnicas en la Europa renacentista y la emergencia posterior de la física galileana.

El papel de los ordenadores remodelando la ciencia y tecnología contemporáneas y abriendo nuevas vías de pensamiento queda bien recogido en la obra ya citada de Stonier, así como en el libro póstumo de L. Pagels (1988): "Los sueños de la razón: el ordenador y el ascenso de las ciencias de la complejidad". A la luz de ambas obras podríamos valorar el curioso caso de la Inteligencia Artificial, diciendo que quizás ha constituido un primer intento sintetizador de esa nueva ciencia, pero excesivamente prematura y muy lastrada todavía por las tareas filosóficas no resueltas, y por ello posiblemente ha llevado a una serie de distorsiones profundas acerca de la naturaleza de la inteligencia.

El nuevo campo de Artificial Life ha desplazado el foco de investigación hacia objetivos biológicos más plausibles - ya no se trata de capturar la inteligencia de un cerebro humano, sino la "lógica de la vida", y de imitarla en los programas de ordenador, robots autónomos, algoritmos genéticos, etc. (Véase Langton, 1989; Langton et al., 1991). Como revulsivo intelectual su interés es indiscutible; pero todavía es pronto para saber si la "vida artificial" definitivamente va a abrir una línea de pensamiento original, o si por el contrario se encamina hacia la repetición de los dudosos éxitos científicos de la inteligencia artificial, incurriendo el mantenimiento de postulados computacionales tan equívocos como la tesis de Turing-Church. Para el biólogo teórico R. Rosen (1993), los signos son de que Artificial Life va a quedar encerrada en una "bio-mimesis", en una imitación de facetas parciales del comportamiento biológico parecidas a los famosos autómatas mecánicos del siglo XVIII, pero ahora efectuados por medio del ordenador.

Otra disciplina relacionada con las anteriores, conocida como "molecular computing" (ya la hemos citado en 2.3), y que plantea el uso de moléculas biológicas (enzimas y proteínas) para el desarrollo de procesamientos artificiales de la información (M. Conrad, 1992), es uno de los campos que muestran mayor solidez y posibilidades futuro, a pesar de todas sus presentes limitaciones.

5.2. Una "perspectiva informacional" genuina aparece también en diversos autores de psicología, humanidades y ciencias sociales. Señalemos que, paradójicamente, las ideas y modelos basados en el ordenador parecen haber provocado en la psicología y la neurociencia cognitiva un periodo de cierto escolasticismo y estancamiento conceptual; y ello no deja de ser paradójico porque paralelamente la neurobiología molecular y la neurofisiología han avanzado velozmente. En humanidades se podrían destacar trabajos como el del historiador G. Ifrah (1985), acerca de las cifras y el origen social de los sistemas de cálculo, y antes que él la monumental obra de J. Needham (1954) sobre la ciencia y el pensa-

Scire. 1 : 1 (en.-jun. 1995). 
miento chinos, escrita desde la óptica de una filosofía whiteheadiana, sumamente sensible al "organicismo" subyacente en los procesamientos sociales de la información.

Destaquemos la compilación efectuada en ciencias sociales por J.K. De Vree (1990); la influencia de las ideas termodinámicas de "sistemas abiertos" del físico Prigogine han encontrado eco en este sociólogo, así como en otros estudiosos de la complejidad de los sistemas sociales en la línea del Santa Fe Institute. Asimismo algunas escuelas de economía y filosofía política han incorporado a su base conceptual ideas informacionales como la Teoría de Juegos de von Neuman y Morgensten (basándose sobre todo en la visión biológica-informacional desarrollada en la obra de R. Axelrod, 1984).

En la reivindicación explícita de una Ciencia de la Información, con el más amplio alcance epistemológico, hay que reseñar también a un autor del campo de la Información documental (R.C. Brookes, 1974) y a un pionero de la Ingeniería del conocimiento (G. Scarrot, 1986).

¿Vamos hacia una ciencia unificada de la Información? Quizás sí, pero todavía carecemos de un sistema conceptual adecuado y de un sistema experimental modelo. Las ideas que hemos expuesto aquí, coincidiendo hasta cierto punto con autores como Thompson, Margulis, Koshland, etc., conducen a que el sistema celular más simple puede servirnos como tal modelo experimental para una nueva concepción más amplia, no ya de la inteligencia, sino más bien de la automodificación y las "dinámicas intelectivas". En sí esos sistemas modelo equivalen a un regalo de la naturaleza, que nos permite hacernos fuertes en la exploración de una parte reducida del nuevo campo de conocimiento, y a partir de ahí avanzar sustancialmente. Tal fue el caso del átomo de hidrógeno para la física cuántica, o del sistema solar para el desarrollo de la dinámica newtoniana.

5.3. Respecto a las relaciones mutuas entre las ciencias (incluyendo ahí su carácter de "sistema" conjunto y su relación con la sociedad en cuanto tal sistema conjunto), el aspecto que vamos a desarrollar aquí tiene que ver con las discusiones — realizadas más bien durante las dos pasadas décadas- acerca del reduccionismo entre las ciencias. Dos son las ideas concretas que vamos a lanzar al respecto: Primero, que en general se ha polemizado acerca del reduccionismo desde una visión fisicalista, bastante estrecha, que establecía una jerarquía de "estratos horizontales" entre las ciencias. Y segundo, que en todo caso la problemática reduccionista es secundaria ante el principal problema que tienen los sistemas basados en conocimiento: el de la integración.

El programa reduccionista triunfó espectacularmente tras la culminación más o menos feliz por parte de la física de su segunda revolución cuántica en los años 50, y su extensión a determinadas ramas de la Química. Numerosos autores, en 
consonancia con la hegemonía filosofíca del positivismo lógico, defendieron algo parecido a la formación de una "Gran Cadena del Conocimiento" entre todas las ciencias. El modelo implícito consistía en que, paralelamente a los "estratos" materiales de la realidad, otro sistema de estratos semejantes podía formarse entre las ciencias. Obviamente la jerarquía superior correspondía a la Física (a una física matematizada elaborada según la metodología positivista). La figura 1 ilustra esta forma de ver el sistema de las ciencias, que curiosamente era compartida también por sus adversarios "anti- reduccionistas", como von Bertalanffy y otros seguidores de la Teoría de Sistemas —éstos, lo que argumentaban era contra la reducibilidad de los estratos.

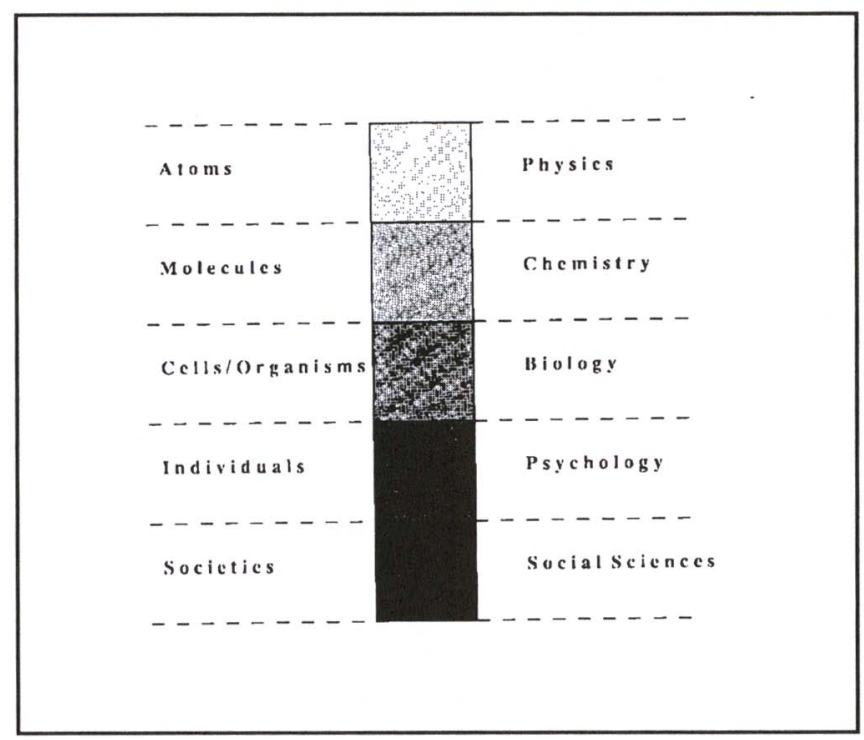

Figura 1

Pero un mínimo análisis de los campos y subdisciplinas que abarcan la física y la química, y de las relaciones de estas con las otras grandes ciencias, nos podría llevar con igual peso epistemológico a otra visión alternativa "vertical". Hemos representado en la figura 2 esa posibilidad.

En una figura similar (fig. 3) recogemos lo que comentábamos acerca de una posible ciencia de la información; siguiendo a Stonier (1990), podríamos situar-

Scire. 1 : 1 (en.-jun. 1995). 
la hipotéticamente cubriendo incluso un territorio más extenso que el de la propia física, aunque la situación actual de algunos de los campos informacionales especializados vendría representada mejor por el cuadrado desplazado; es decir, a medio camino del mundo biológico y físico-químico.

Aparentemente, a grandes rasgos la representación elemental de las ciencias muestra una cierta antítesis entre dos posibilidades: una de "estratos" horizontales y otra de "perspectivas" verticales (fig. 1 versus fig. 2). ¿Cómo podríamos tomar partido por una u otra alternativa? La mera argumentación no parece ser el mejor camino (pocos debates han sido tan aburridos como los que hubo acerca del problema del reduccionismo). La sugerencia que aquí hacemos consiste en que ha de ser el propio estudio empírico de la estructura de la ciencia el que ha de proporcionar una clara respuesta al respecto. La "Geografía de la Ciencia", tal y como Small y Garfield la han propuesto (1985), conduce a representaciones sofisticadas de los propios campos científicos y de sus interacciones mutuas. $\mathrm{Si}$ aceptamos la pertinencia de la presente disyuntiva entre una visión horizontal y otra vertical, es ahí donde podríamos encontrar los elementos conceptuales para decidirnos por una u otra opción.

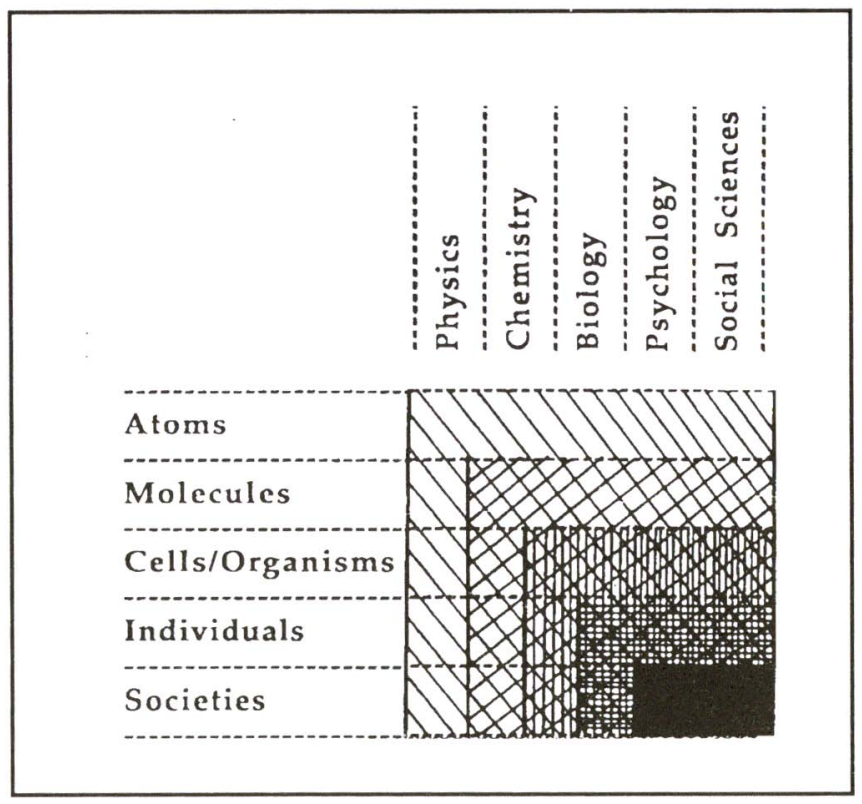

Figura 2

Scire. $1: 1$ (en.-jun. 1995). 
5.4. Aclaremos que el programa reduccionista no pretendemos aquí que sea una tarea "equivocada", pero sí secundaria. El darle la prioridad a esa visión jerárquica de las relaciones entre las ciencias implica una auténtica distorsión de pensamiento, que no deja de tener graves consecuencias. Discutamos más este punto. Buscar la continuidad entre los desarrollos científicos es conveniente, y en algunos casos ha conducido a grandes resultados (Química), aunque en otros ha llevado a errores de bulto (el conductismo en Psicología y Ciencias Sociales). Aquí postulamos que el problema principal de un sistema científico no es el de la continuidad, sino el de la integración. El énfasis unilateral en la reducción fisicalista es en sí un sucedáneo de integración. Conduce al error inmediato de pretender tomar como modelo una única perspectiva disciplinar para la obtención y acumulación de conocimiento - un único método científico. Como vamos a argumentar a continuación, aunque ese empeño fuera acertado, aunque el programa reduccionista pudiera completarse y desde la física fuera posible desplegar gradualmente todo el conjunto de las disciplinas científicas, aún sería cuestionable la importancia de esa faceta dentro del conjunto de las actividades científicas reales.

Las ciencias representan la acumulación de conocimiento por parte de nuestra sociedad acerca del mundo que le rodea, incluyéndose ella misma en la exploración. En este sentido, las ciencias representan captaciones parciales, especializadas, de información por parte del organismo social — lo mismo que las modalidades sensoriales suponen para un sistema nervioso. Es fácil ver que si un sistema nervioso se planteara también el reducir todos sus sentidos a la manera

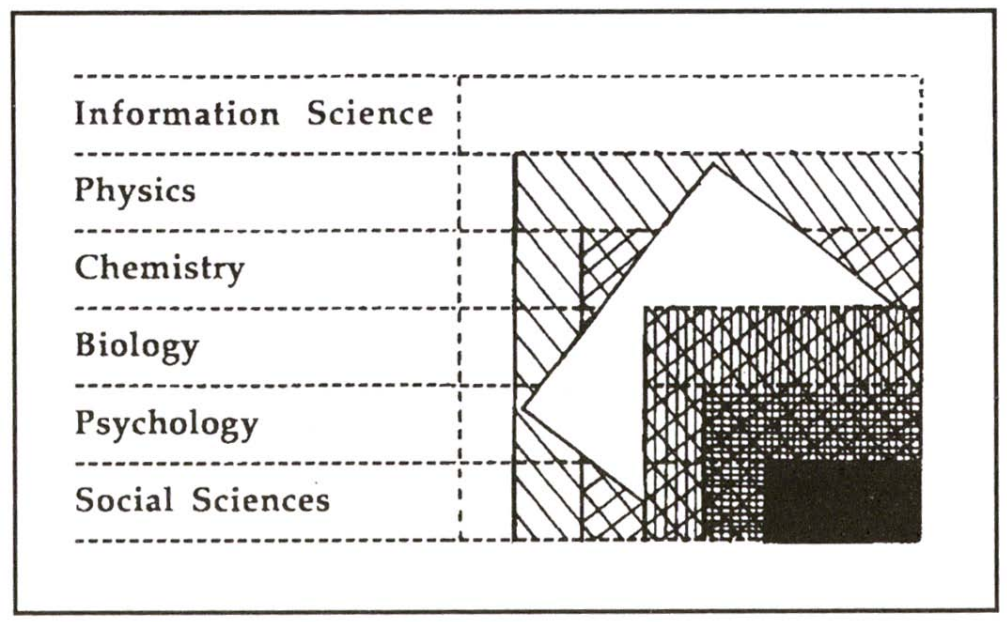

Figura 3

Scire. 1 : 1 (en.-jun. 1995). 
fisicalista (como prioridad de su propia labor), no le sería excesivamente útil para guiar su acción en el mundo que le rodea. Jerarquizar todas las entradas sensoriales: primero la visión, detrás quizá el oído, la propiocepción, el olfato, gusto... y luego reducirlas todas a sus proyecciones sobre los elementos del campo precedente. Pero informacionalmente eso tiene muy poco sentido y nada hay más lejos de la actividad cotidiana de un sistema nervioso. La mayor parte de sus neuronas tienen que ver con la mezcla de modalidades, con la formación de complejos "mosaicos" heterogéneos en que están integrados fragmentos de múltiples facetas sensoriales primarias.

El problema integrativo (de genes, de modalidades sensoriales, de conocimientos científicos) es el gran problema cotidiano que las "sociedades" basadas en conocimiento han de estar resolviendo continuamente. La fertilidad de un sistema científico, o de un sistema nervioso, o de un robot autónomo, o de una bacteria, no consiste en elaborados desarrollos internos que atienden sólo a un tipo de acontecimientos del medio, sino más bien en saber responder a los problemas globales que la realidad impone y saber desplegar los conocimientos oportunos mediante la combinación adecuada de perspectivas (de almacenes parciales de conocimientos especializados). El gran problema que tenemos al afrontar científicamente la realidad - y lo mismo les pasa a los otros sistemas - es que nunca podemos estar seguros de la perspectiva o mezcla de perspectivas que han de prevalecer en nuestro encuentro con ella. El "accidente" significa precisamente eso, el haberse equivocado respecto a la prevalencia de un tipo de conocimiento en un micro-ambiente determinado. Equivocarse de "prevalencia" es el error humano, el accidente o el mal diseño, la irrupción de lo que suponíamos controlado...

Habría que enfatizar que en el mundo del conocimiento no basta con tener el adecuado juego de perspectivas parciales en la cabeza, sino que hay que saber usarlas y combinarlas de las más diversas maneras. El sistema educativo ha de servir literalmente para eso, para incitar y acostumbrar al juego de perspectivas; y no para atragantar de conocimientos especializados que se enseñan como si fueran el moderno equivalente a la verdad absoluta de las religiones. La separación del conocimiento en segmentos especializados es necesaria pero ha de ir cuidadosamente compensada por mecanismos interdisciplinares a todos los niveles; sin esos mecanismos compensatorios, el empobrecimiento de la enseñanza y de la propia comunidad científica es inevitable. Bien mirado, el cubrir la realidad parsimoniosamente con una pluralidad de conocimientos variados no deja de ser un arte, y como todas las artes tiene un fondo individual intransferible y a la vez requiere una educación cuidadosa que combine y compense una pluralidad de factores contrapuestos.

Desde esta visión de la ciencia como "sensorium" especializado del organismo social, no son pocas las extensiones que podríamos hacer. Desde la propia

Scire. 1 : 1 (en.-jun. 1995). 
organización de la comunidad científica, su necesidad de medios internos de comunicación (revistas, libros, congresos, etc), la interfase de esta comunidad con el resto del organismo social (interacción con la técnica y las profesiones, la difusión de la ciencia, cómo organizar las políticas científicas, la dinámica de las instituciones, etc), y también las múltiples "mezclas" e integraciones transitorias (o permanentes) que se producen entre las ciencias: psico-sociología, bio-psicología, socio-biología, bio-química, físico-química, bio-matemáticas... como ocurre en las mezclas de las variedades sensoriales de un sistema nervioso. Quizás el desarrollo de la "Geografía de la Ciencia" nos va a acabar mostrando algo que no va a ser ni horizontal ni vertical, como discutíamos antes, sino muy parecido a una "ecología de campos", como las mezclas de los procesamientos cerebrales, como el robot autónomo, como los propios ecosistemas. Frente a toda esta complejidad intrínseca que aparece en la dinámica de la empresa científica, la ficción fisicalista que ha pretendido el reduccionismo representa más bien un mito corporativo de científicos especializados, una actitud fundamentalista que ignora el sentido de importancia en los problemas que está afrontando el sistema de las ciencias en su interacción con la sociedad (y que de hecho supone un flaco apoyo para la explicitación de los mismos).

Por último, recordar a un pionero, a la primera persona "moderna" que contempló el sistema de ciencias como lo que básicamente es: como una acumulación social de conocimiento, trabajosamente construida, que necesitamos en primer lugar para resolver los problemas de la propia vida social. Se llamaba Luis Vives, y corría el siglo XVI...

\section{Referencias citadas}

Axelrod, R. (1984). The Evolution of Cooperation. New York : Basic Books, 1984.

Brookes, B. C. (1974). Robert Fairthorne and the scope of information science. // Journal of Documentation. $30: 2$ (1974) 139-152.

Brooks, R. (1986). A robot that walks: Emergent behaviors from a carefully evolved network. // Neural Computation. 1 : 2 (1986) 253-262.

Brooks, R. (1991). Intelligence Without Reason. // I. J. C.A. I. (1991).

Collins, J. K. (1991). On the Automation of Knowledge Within Central Nervous Systems: Introduction to Duality Theory. Unpublished Manuscript.

Conrad, M. (1990). Molecular Computing. // Advances in Computing. M. Yovits ed. New York Academic Press, New York, 1990.

Conrad, M. (1992). Molecular Computing: The Lock-Key Paradigm. // Computer. 25 : 11 (1992) 11-20.

Farmer, J. D. (1990). A Rosetta Stone for Connectionism. // Physica D. 42 (1990) 153187.

Forrest, S. (1990). Emergent Computation: Self-organizing, Collective, and Cooperative Phenomena in Natural and Artificial Computing Networks. // Physica D. 42 (1990) 1-

Scire. $1: 1$ (en.-jun. 1995). 
11.

Huberman, B.A. (1988). The Behavior of Computational Ecologies. // The Ecology of Computation / B. Huberman ed. North Holland : Elsevier Science, 1988.

Huberman, B.A. ; Hogg T. (1992). The Emergence of Computational Ecologies. // SFI 1992 Lectures in Complex Systems. In press.

Ifrah, G. (1985). Les chiffres, ou l'histoire d'une grande invention. Paris : Editions Robert Laffont, 1985. Ed. esp.: Madrid : Alianza, 1987.

Jacob, F. (1970). La logique du vivant. Paris : Gallimard, 1970. Ed. esp.: Barcelona : Salvat 1986.

Langton, Ch. (1989). Artificial Life I. Redwood City CA : Addison-Wesley, 1989.

Langton, CH. ; Taylor, C. ; Farmer, J.. ; Rasmussen, S. (1991). Artificial Life II. Redwood City CA : Addison-Wesley, 1991.

LeRoith, D. ; Roth, J. (1984). Vertebrate hormones and neuropeptides in microbes: evolutionary origin of intercellular communication. // Frontiers in Neuroendocrinobiology. New York : Ravett Press, 1984.

Margulis, L. (1970). Origin of Eukaryotic Cells. New Haven NY: Yale University Press, 1970.

Margulis, L. (1982). Early Life. Jones and Barlett Publishers, 1982. Ed. esp.: Reverté, 1986.

Marijuán P.C. (1991). Enzymes and Theoretical Biology : Sketch of an Informational Perspective of the Cell. // BioSystems. 25, (1991) 259-273.

Marijuán, P.C. ; Westley, J. (1992). Enzymes as Molecular Automata : A Reflection on some Numerical and Philosophical Aspects of the Hypothesis. // BioSystems. 27 (1992) 97-113.

Maturana, H. ; Varela, F. (1987). The Tree of Knowledge. Shambahala ; Boston MA: New Science Library, 1987.

McLuhan, M. (1964). Understanding Media : The Extension of Man. McGraw-Hill Books, 1964. Ed. Esp.: Diana, 1969.

Monod, J. (1970). Le hasard et la necesité. Paris : Editions du Seuil, 1970. Ed. esp.: Barral, 1981.

Needham, J. (1954). Science and Civilization in China. Cambridge UK. Cambridge Un. Press, 1954. 7 vols.

Pagels, H.R. (1988). The Dreams of Reason : The Computer and the Rise of the Sciences of Complexity. New York : Simon and Schuster, 1988. Ed. esp.: Gedisa, 1991.

Pavans de Ceccatty, M. (1974). Origin of the Integrative Systems. // Perspectives in Biology and Medicine. 17 (1974) 319.

Purves, D. (1988). Body and Brain: A Trophic Theory of Neural Connections. Cambridge, Mass. : Harvard Un. Press, 1988.

Rosen, R. (1993). On Psycho-mimesis. Forthcoming.

Scarrot, G. (1986). The need for a "science" of Information. // J. Inform. Technol. $1: 2$ (1986) 33-38.

Shapiro, J. A. (1988). Bacteria as Multicellular Organisms. // Scientific American. (June

Scire. 1 : 1 (en.-jun. 1995). 
1988).

Small, H. ; Garfield, E. (1986). The geography of science : disciplinary and national mappings. // Jour. Infor. Sci. 11 (1986) 147.

Sonea, S. (1990). Bacterial (Prokaryotic) Communication. // The Semiotic Web / T. A. Sebeoek, ed. Berlin : Mouton de Gruyter, 1990.

Stonier, T. (1990). Information and the internal structure of the universe : An exploration into Information Physics. London : Springer Verlag UK, 1990.

Thompson, W. I. (1989). Imaginary Landscape : Making Worlds of Myth and Science. New York : St. Martin Press, 1989.

Varela, F. ; Thompson, E. ; Rosch, E. (1991). The embodied mind : Cognitive science and human experience. Cambridge, Mass. : MIT Press, 1991.

Winograd, T. ; Flores, F. (1986). Understanding Computers and Cognition : A New Foundation for Design. Norwood, N. J. : Ablex Publishing Corporation, 1986.

Yonezawa, A. (1992). The Real World Computing Program : MITI's Next Computer Research Initiative. // Science. 258 (1992) 581-582.

Scire. 1 : 1 (en.-jun. 1995). 